\title{
Author Correction: Dissymmetry enhancement in enantioselective synthesis of helical polydiacetylene by application of superchiral light
}

Chenlu He${ }^{1}$, Guang Yang${ }^{2}$, Yan Kuai ${ }^{3}$, Sizhen Shan ${ }^{1}$, Lin Yang ${ }^{1}$, Jingang Hu', Douguo Zhang ${ }^{3}$, Qijin Zhang ${ }^{1}$ \& Gang Zou ${ }^{1}$

Correction to: Nature Communications https://doi.org/10.1038/s41467-018-07533-y, published online 30 November 2018.

The original version of the Article contained an error in Fig. 2 in which the TEM images in Fig. $2 b$ and $d$ were incorrect. The correct version of Fig. 2 is:

a
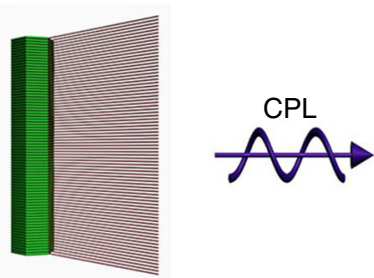

b

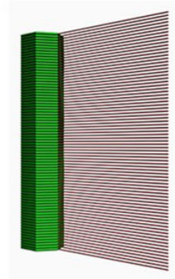

SCL

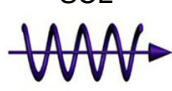

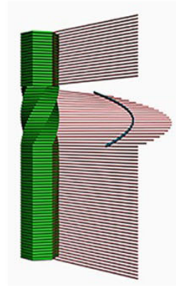
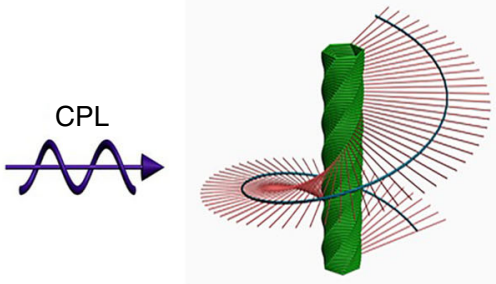

b

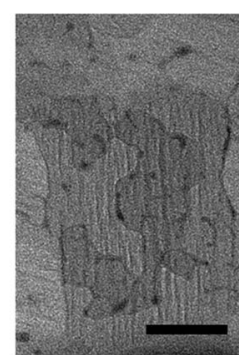

d

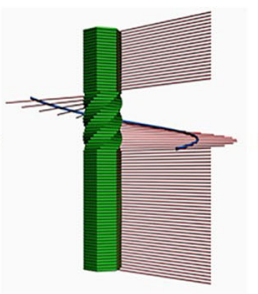

SCL $\forall A$$$
\text { 西 }
$$

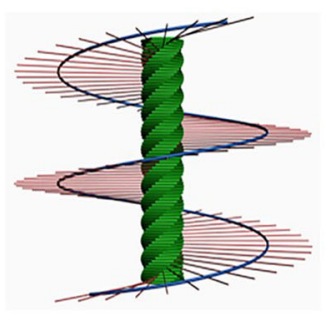


which replaces the previous incorrect version:

a
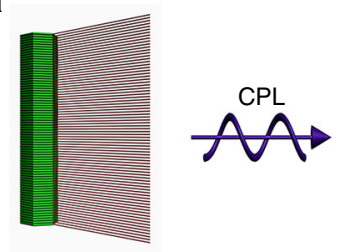
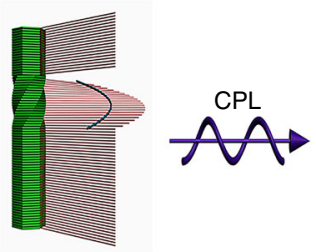

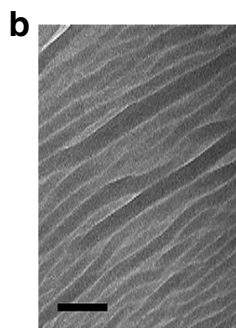

d

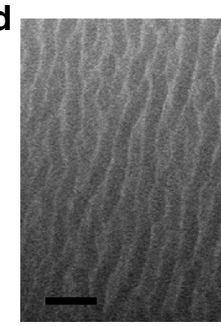

Additionally, the seventh sentence of the 'Mechanism for the dissymmetry enhancement of SCL field' section of the Methods originally incorrectly read 'Since the relative light intensity ratio $R=\frac{I_{2}}{I_{1}} \frac{E_{2}^{2}}{E_{1}^{2}}$, the dissymmetry factor near the nodes of SCL field can be expressed as ' $g_{\mathrm{SCL}}=g_{\mathrm{CPL}} \times \frac{(1+\sqrt{R})}{(1-\sqrt{R})}$ '. The correct version states ' $R=\frac{I_{2}}{I_{1}}=\frac{E_{2}^{2}}{E_{1}^{2}}$ instead of ' $R=\frac{I_{2}}{I_{1}} \frac{E_{2}^{2}}{E_{1}^{2}}$. This has been corrected in both the PDF and HTML versions of the Article.

Published online: 02 May 2019

(c) (i) Open Access This article is licensed under a Creative Commons Attribution 4.0 International License, which permits use, sharing, adaptation, distribution and reproduction in any medium or format, as long as you give appropriate credit to the original author(s) and the source, provide a link to the Creative Commons license, and indicate if changes were made. The images or other third party material in this article are included in the article's Creative Commons license, unless indicated otherwise in a credit line to the material. If material is not included in the article's Creative Commons license and your intended use is not permitted by statutory regulation or exceeds the permitted use, you will need to obtain permission directly from the copyright holder. To view a copy of this license, visit http://creativecommons.org/licenses/by/4.0/.

(C) The Author(s) 2019 